\title{
NEW RESULTS RELATED TO THE CONVEXITY \\ OF THE BERNARDI INTEGRAL OPERATOR
}

\section{GEORGIA IRINA OROS}

Abstract. In this paper we prove the convexity of the image of a close-to-convex function by the Bernardi integral operator given by

$$
L_{\gamma}(f)(z)=F(z)=\frac{\gamma+1}{z^{\gamma}} \int_{0}^{z} f(t) t^{\gamma-1} d t, \quad z \in U .
$$

This result extends the result obtained by N. Pascu in [9], where it has been shown that the Bernardi operator transforms a close-to-convex function into a close-to-convex function under certain conditions.

Mathematics subject classification (2010): 30C45, 30A20, 34A40.

Keywords and phrases: Analytic function, univalent function, integral operator, convex function, closeto-convex function.

\section{REFERENCES}

[1] S. D. Bernardi, Convex and starlike univalent functions, Trans. Amer. Math. Soc., 135 (1969), 429-446.

[2] Z. Lewandows Ki, S. S. Miller AND E. ZlotkiEwicZ, Generating functions for some classes of univalent functions, Proc. Amer. Math. Soc., 56 (1976), 111-117.

[3] S. S. Miller, P. T. Mocanu, Differential subordinations and univalent functions, Michigan Math. J., 28 (1981), 157-171.

[4] S. S. Miller, P. T. Mocanu, Differential subordinations and inequalities in the complex plane, J. of Diff. Eqns. 67, 2 (1987), 199-211.

[5] S. S. Miller, P. T. Mocanu, Classes of univalent integral operators, J. Math. Anal. Appl., 157, 1 (1991), 147-165.

[6] S. S. Miller, P. T. Mocanu, Differential subordinations. Theory and applications, Pure and Applied Mathematics, Marcel Dekker, Inc., New York, 2000.

[7] P. T. MocAnu, T. BulboacĂ, ŞT. G. SăLĂGEAn, Teoria geometrică a funcţiilor univalente, Casa Cărţii de Ştiinţă, Cluj-Napoca, 1999.

[8] G. I. OROS, New results related to the convexity and starlikeness of Bernardi integral operator, Hacettepe Journal of Mathematics and Statistics, vol. 38 (2) (2009), 137-143.

[9] N. N. PASCU, Alpha-close-to-convex functions, Romanian Finish Seminar on Complex Analysis, Springer Berlin, 1979, 331-335. 